\title{
Determination of Optimal Hormone and Mineral Salts Levels in Tissue Culture Media for Callus Induction and Growth of Industrial Hemp (Cannabis sativa L.)
}

\author{
Xoe Thacker, Kayla Thomas, Matthew Fuller, Shannon Smith, John DuBois* \\ Department of Biology and the Tennessee Center for Botanical Medicine Research, Middle Tennessee State University, Murfreesboro, \\ TN, USA \\ Email: *John.dubois@mtsu.edu
}

How to cite this paper: Thacker, X., Thomas, K., Fuller, M., Smith, S. and DuBois, J. (2018) Determination of Optimal Hormone and Mineral Salts Levels in Tissue Culture Media for Callus Induction and Growth of Industrial Hemp (Cannabis sativa L.). Agricultural Sciences, 9, 1250-1268. https://doi.org/10.4236/as.2018.910088

Received: September 19, 2018

Accepted: October 22, 2018

Published: October 25, 2018

Copyright $\odot 2018$ by authors and Scientific Research Publishing Inc. This work is licensed under the Creative Commons Attribution International License (CC BY 4.0).

http://creativecommons.org/licenses/by/4.0/

\begin{abstract}
Historically, industrial hemp (Cannabis sativa L.) has been a valuable source of metabolites and compounds, such as cannabidiols. There is a need for large amounts of plant tissue to be grown under controlled environments, and plant tissue culture is one unique way to yield this tissue. The purposes of this study were to determine: 1 ) the optimal concentrations $(\mu \mathrm{M}) /$ ratios of auxin:cytokinin in media and; 2) the optimal mineral salts formulation for callus induction and callus growth in select hemp cultivars. To find the optimal concentration/ratios, 16 different combinations of auxin:cytokinin and three different mineral salts formulations were evaluated. The three mineral salts formulations tested were MS salts, MB5D1K and an MTSU formulation. The top performing hormone formulations were determined to be equal concentrations $(1: 1,2: 2,3: 3 \mu \mathrm{M})$ of auxin and cytokinin. The top performing media hormone formulations for callus induction were determined to be 2:1, 2:2, 2:3, and 3:2 $\mu \mathrm{M}$ (auxin:cytokinin). The optimal mineral salts formulation was determined to be MD5D1K. Therefore, the overall optimal media formulation for hemp callus production would be MB5D1K salts with the concentration/ratio of 2:2 $\mu \mathrm{M}$ (auxin:cytokinin).
\end{abstract}

\section{Keywords}

Industrial Hemp, Cannabis Sativa, Tissue Culture, Hormones, Mineral Salts, Callus

\section{Introduction}

Industrial hemp (Cannabis sativa L.) has been a historical source for various 
compounds and metabolites [1]. One group of compounds harvested from industrial hemp is cannabidiol (CBD), which does not include tetrahydrocannabinol (THC), the cannabinoid found in marijuana plants that is responsible for the psychological effects. Industrial hemp produces very low amounts of THC (less than 0.3\%). Cannabinoids are unique chemicals that the plant produces for various reasons (i.e., defense mechanism for predators). Cannabidiols are one specific type of cannabinoid produced by industrial hemp [2]. Several different products come from industrial hemp through utilization of various parts of the plant. For instance, hemp fiber from the stem has been used for textiles and construction materials, while the oil from the seeds is used in cosmetics and other personal care items [1]. In addition to the industrial uses of the plant, there is a growing interest in the pharmaceutical applications of industrial hemp.

Cannabidiols have been used in the treatment of epilepsy, as an appetite enhancer, as an antidepressant, and also as an analgesic [1]. Researchers have also discovered the potential benefits of CBD's as an anti-inflammatory and aid in sleep support [3]. Other products containing CBD have shown anti-stress and relaxation qualities without the drowsy feeling that other anti-stress and anxiety medications may cause [3]. As the plant produces a wide variety of cannabinoids, on which research is just beginning, there is a need for large amounts of compound-producing plant tissue to be grown in controlled environments. There are various procedures to yield plant tissue, but one unique way is through tissue culture.

The tissue culture method breaks tradition, in that, there is no soil or sunshine needed to initiate production and growth of the cells. In the wild and in agriculture, there are many confounding variables that can impact plant growth and compound production. Plant tissue culture is one method to ensure the least amount of confounding variables for plant growth. In addition, this in vitro approach is the quickest and most reliable way to preserve a germ line that has been bred for the production of specific compounds. The process involves aseptic cultures, exemplified through thorough sterilization of plant tissue, a nutrient medium containing mineral salts, sugars and hormones for the explant tissue to thrive, and the production of callus as the explant utilizes the nutrients in the medium [4].

The purposes of this study were to determine: 1) the optimal concentrations/ratios of auxin-to-cytokinin; and 2) to determine an optimal mineral salts mix in media to generate and grow tissue callus for select cultivars of industrial hemp.

\section{Methods}

\subsection{Media Preparation}

The three different nutrient salts media were Murashige-Skoog (MS) salts media [4] that contained MS salts with $0.9 \%$ agar along with $5 \mu \mathrm{M}$ 2,4-Dichlorophenoxyacetic acid (2,4-D) and $1 \mu \mathrm{M}$ Kinetin, MB5D1K media consisting of MS salts, $0.8 \%$ agar, $3 \%$ sucrose, $0.05 \mathrm{~g} / \mathrm{mL}$ solution of myo-Inositol, 
and $500 \mu \mathrm{L}$ solution of Gamborgs vitamins, $5 \mu \mathrm{M} 2,4-\mathrm{D}$ and $1 \mu \mathrm{M}$ Kinetin and an experimentally-determined medium called the MTSU medium, which contains MS salts, $0.8 \%$ agar, $3 \%$ sucrose, $1 \mathrm{mg} / 100 \mathrm{~mL}$ of Thiamine, $10 \mathrm{mg} / 100 \mathrm{~mL}$ of casein, and $0.4 \mathrm{mg} / 100 \mathrm{~mL}$ of nicotinic acid.

To assess the hormone concentrations/ratios, 16 different concentrations/ratios were tested using the MS salts medium. Auxin (2,4-D) and cytokinin (kinetin) were the hormones that were varied in the media, while the concentrations of everything else were held constant (i.e., deionized water, sucrose, salts). Table 1 shows the hormone array and the variation among media hormone concentrations.

All media supplies were obtained through PhytoTechnology Laboratories (Lenexa, KS). Media were prepared following the procedures outlined by Murashige and Skoog [5], along with the adjustments noted above. All media were set to a $\mathrm{pH}$ of 5.6 - 5.8, by adding either sodium hydroxide or hydrochloric acid. The media were then autoclaved at $121^{\circ} \mathrm{C}$ for 20 minutes at slow exhaust, cooled to $60^{\circ} \mathrm{C}$ and poured into $100 \mathrm{~mm} \times 15 \mathrm{~mm}$ Petri plates. The petri plates were then sealed with parafilm and stored in a refrigerator until needed.

\subsection{Collection of Plant Tissue}

The cultivars used in these experiments were Landrace, Futura, Canda, Joey, CFX-2 and Cherry $\times$ Workhorse. All plants were grown in a greenhouse located in Middle Tennessee, USA. The greenhouse was maintained at $22^{\circ} \mathrm{C}, 70 \%$ relative humidity and natural sunlight. The plant tissues used in this project were leaf tissue. In order to collect the tissue, stem cuttings $(10-15 \mathrm{~cm})$ were made and brought to the lab to undergo sterilization processes.

\subsection{Plant Tissue Sterilization}

In a sterilized biological safety hood, the plant tissue was sterilized using techniques developed by Leguillon et al. [6] and Odnevall et al. [7]. These techniques ensure (to the best ability) that the tissues are clean, and free of any fungus, bacteria, or mold spores. Leaf tissues were exposed to a 30 second bath in $70 \%$ ethanol, followed by a 20 minute soak in $2.5 \%$ bleach mixed with $1 \%$ surfactant (Dawn Ultra antibacterial hand soap) on a rotary shaker at $100 \mathrm{RPM}$, then rinsed three times with sterile deionized water.

Table 1. Auxin and cytokinin concentrations along with auxin:cytokinin ratios.

\begin{tabular}{ccccc}
\hline \multirow{2}{*}{$\operatorname{Auxin}(\mu M)$} & \multicolumn{4}{c}{ Cytokinin $(\mu M)$} \\
\cline { 2 - 5 } & $\mathbf{0}$ & $\mathbf{1}$ & $\mathbf{2}$ & $\mathbf{3}$ \\
\hline $\mathbf{0}$ & 0.0 & $0: 1$ & $0: 2$ & $0: 3$ \\
$\mathbf{1}$ & 1.0 & $1: 1$ & $1: 2$ & $1: 3$ \\
$\mathbf{2}$ & 2.0 & $2: 1$ & $1: 1$ & $2: 3$ \\
$\mathbf{3}$ & $3: 0$ & $3: 1$ & $3: 2$ & $1: 1$ \\
\hline
\end{tabular}




\subsection{Plating and Incubation of Explants}

The sterilized leaf tissue was cut into explants in the sterile hood. The tissue was generally cut into 3 cross sections/explants per leaf using a sterile scalpel and tweezers then placed on the appropriate treatment media. Three explants were placed on each Petri dish. The plates were then sealed with parafilm to ensure they did not dry out and to also help minimizing the risk of contamination. All plates were stored in the dark in an incubator at $25^{\circ} \mathrm{C}$ for approximately 30 days. The explant/callus was inspected frequently to ensure contamination had not occurred, and if it had, the callus (if salvageable) was moved to another Petri plate of the same hormone concentration to continue growing. Approximately 30 days after the setup of the experiment, the explants/callus were weighed and then transferred to fresh media for the callus to continue to grow. When the callus was transferred, it was transferred to the same media type. The explants were transferred to new media approximately every 30 days four times (passages), the hormone concentration/ratio and mineral salts media that yielded the most callus was determined through statistical methods for each cultivar.

\section{Data Analysis}

Significant differences between treatments were determined using Analysis of Variance and Holm-Sidak Multiple Comparison Procedures. Statistical analysis was performed using SigmaStat (v3.1) software (www.systat.com).

\section{Results}

This study used six different cultivars of industrial hemp (Canda, Joey, Landrace, Futura, CFX-2, and Cherry $\times$ Workhorse). There were three different mineral salts media formulations (MS salts, MB5D1K, and an MTSU formulation) using five of the six cultivars (Canda, Futura, Joey, CFX-2, and Cherry $\times$ Workhorse). There were 16 varying concentrations/ratios of auxin to cytokinin using five of the six cultivars (Canda, Joey, Landrace, Futura, and CFX-2).

\section{Callus Production}

\section{Mineral Salts}

The maximum amount of tissue callus mass for each cultivar and media type over a five-month period are displayed in Figures 1-5. The greatest callus weight by Canda was $0.56 \mathrm{~g}$ on the MB5D1K medium (Figure 1). The MB5D1K medium was the best callus initiating medium generating $0.33 \mathrm{~g}$ from August $23^{\text {rd }}$-September $23^{\text {rd }}$. The medium that came in second for Canda was the MS salts medium. It yielded $0.33 \mathrm{~g}$ of callus after 5 months with $0.27 \mathrm{~g}$ of callus being grown in the first month. The least amount of callus was grown on the MTSU medium with a maximum of $0.18 \mathrm{~g}$ of callus being produced.

The maximum callus mass for the Futura cultivar was $1.58 \mathrm{~g}$ on the medium MB5D1K. This weight was achieved on November $24^{\text {th }}$ but decreased the following month due to contamination (Figure 2). The second-best medium was 
the MS salts medium that yielded $1.50 \mathrm{~g}$ of callus after 5 months. For the MTSU medium $1.19 \mathrm{~g}$ of callus was grown and was the least amount of callus mass after 5 months.

The maximum callus mass for the Joey cultivar was $3.35 \mathrm{~g}$ on the medium MS salts. This weight was achieved on December $26^{\text {th }}$ (Figure 3 ). The second-best medium was the MB5D1K medium that yielded $1.08 \mathrm{~g}$ of callus after 5 months. The MTSU medium plates were lost due to contamination along with the callus on each plate. Callus could not be weighed or saved to reduce the spread of

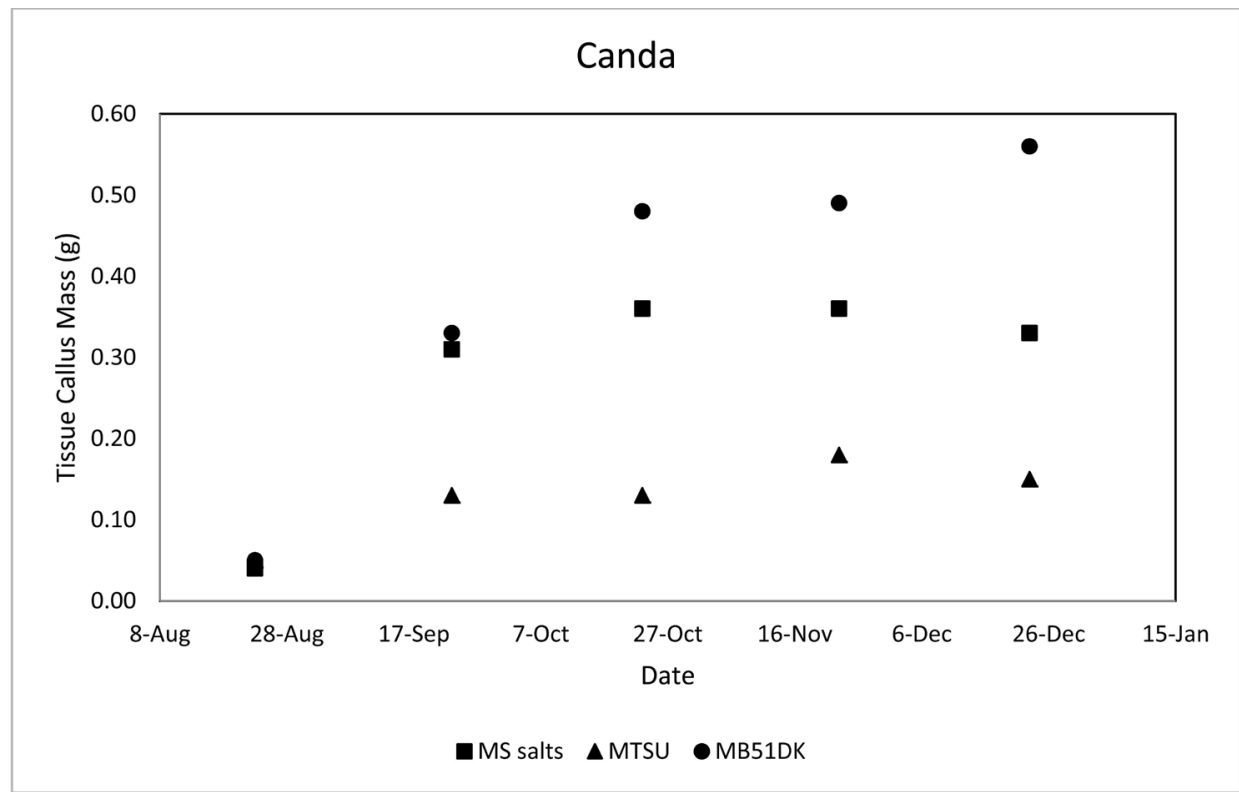

Figure 1. Canda callus mass for MS salts, MTSU, and MB5D1K media from initial plating on August $23^{\text {rd }}$ to final weight on December $23^{\text {rd }}$.

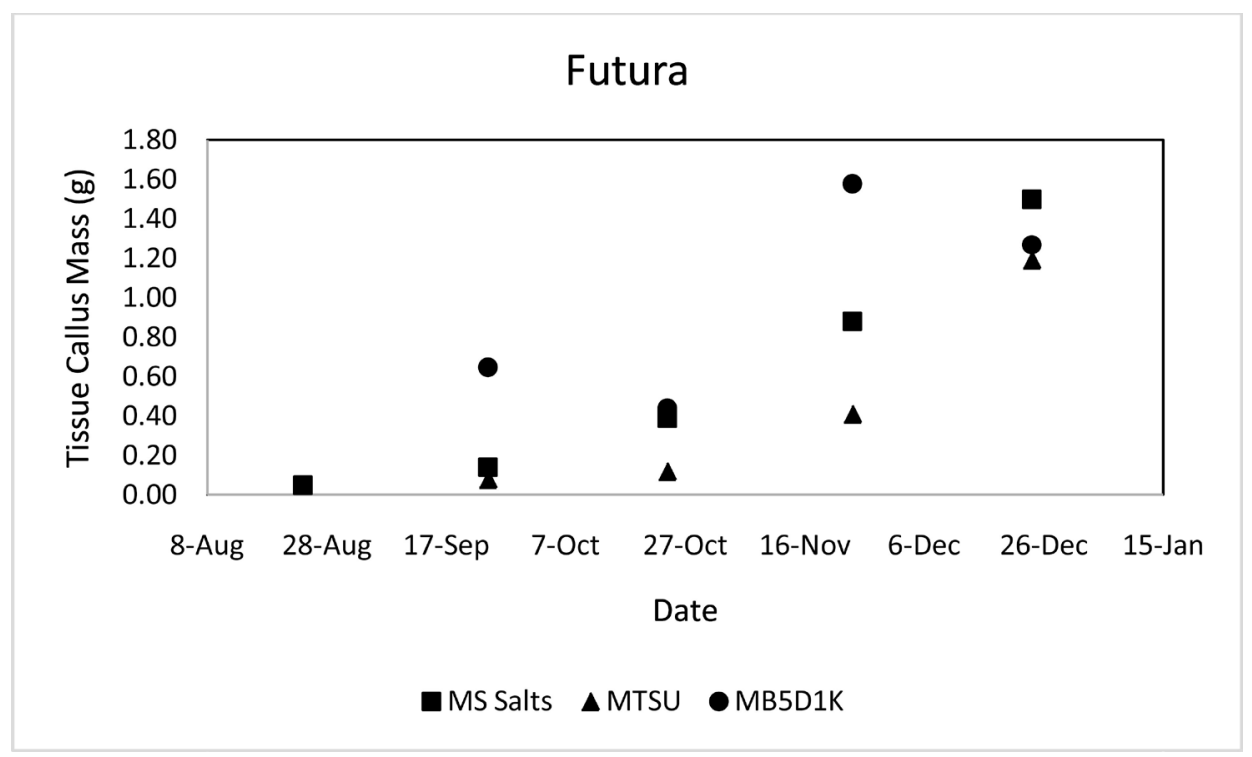

Figure 2. Futura callus mass for MS salts, MTSU, and MB5D1K media from initial plating on August $24^{\text {th }}$ to final weight on December $24^{\text {th }}$. 
contamination to other plates and cultivars.

The maximum callus mass for the CFX-2 cultivar was $2.86 \mathrm{~g}$ on the medium MS salts and this weight was achieved on December $29^{\text {th }}$ (Figure 4). The second-best medium was the MB5D1K medium that yielded $1.79 \mathrm{~g}$ of callus after 5 months. For the MTSU medium $0.66 \mathrm{~g}$ of callus was grown and was the least amount of callus mass after 5 months.

Cherry $\times$ Workhorse was a cultivar that was plated a month later than the other four cultivars and, as a result, was observed for 4 months. The maximum callus mass for this cultivar was $0.78 \mathrm{~g}$ on the medium MS salts. This weight was

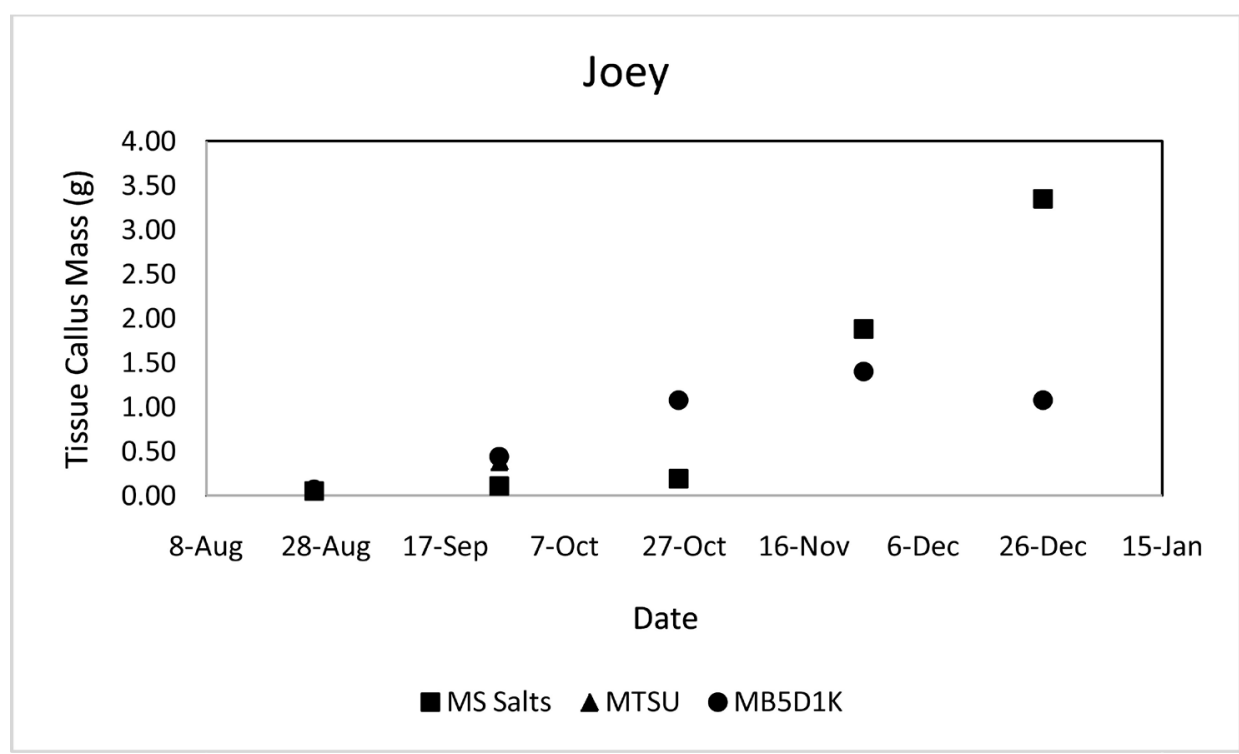

Figure 3. Joey callus mass for MS salts, MTSU, and MB5D1K media from initial plating on August $26^{\text {th }}$ to final weight on December $26^{\text {th }}$.

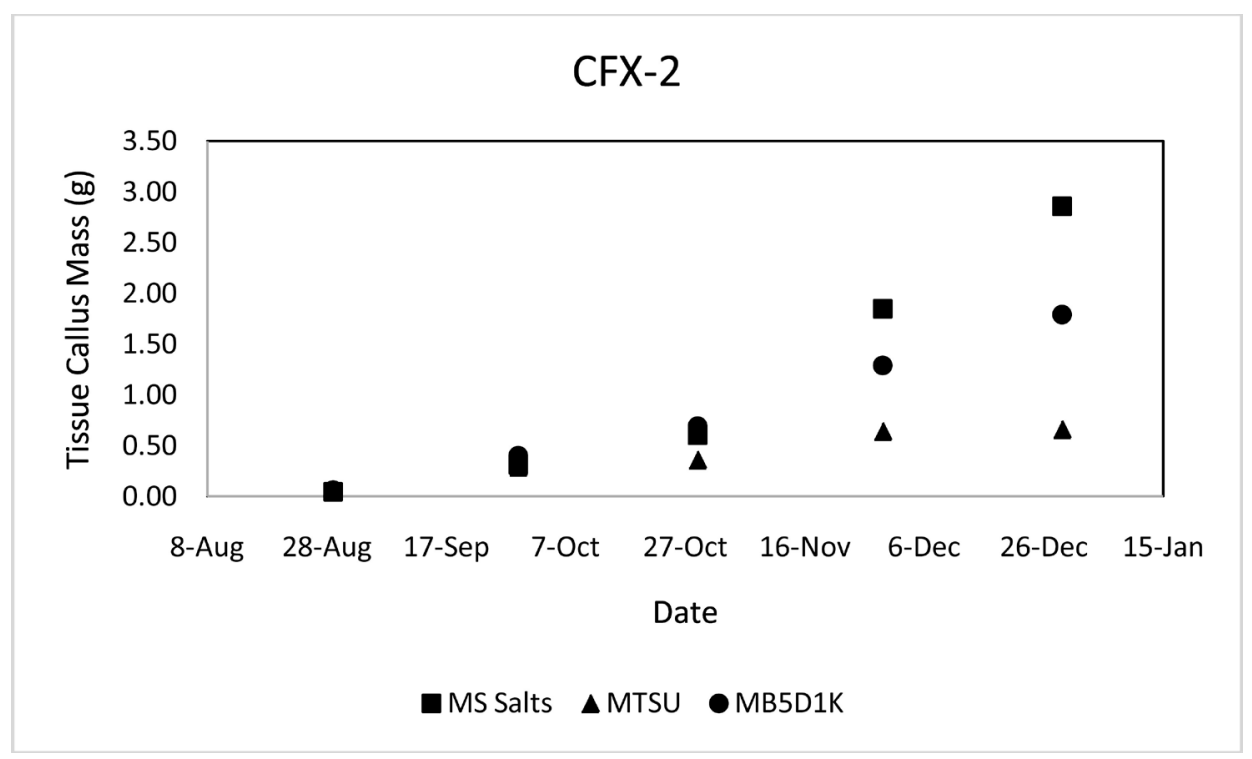

Figure 4. CFX-2 callus mass for MS salts, MTSU, and MB5D1K media from initial plating on August $28^{\text {th }}$ to final weight on December $28^{\text {th }}$. 
achieved on December $28^{\text {th }}$ (Figure 5). The second-best medium was the MB5D1K medium that yielded $1.12 \mathrm{~g}$ of callus after 2 months. The last 3 months were lost to contamination. The MTSU medium plates were lost due to contamination along with the callus on each plate after 2 months, but reached a weight of $0.59 \mathrm{~g}$.

\section{Hormones}

Figures 6-10 highlight the treatments with the maximum response and the maximum amount of callus fresh weight for each cultivar. Each maximum is an average of the three explants originally plated for each treatment. This means some of the maximum weights are actually higher than the averages shown due to callus loss. The best callus-initiating media may also be observed on the graphs.

The maximum callus yielded by Canda was $6.64 \mathrm{~g}$ with the hormone concentrations/ratios of 1:1 (Figure 6). The ratio coming in second was 3:3, yielding, $4.97 \mathrm{~g}$. The best callus-initiating medium was determined to be a $3: 2$ ratio yielding, on average, $0.64 \mathrm{~g}$ from January 27 th-Febuary $24^{\text {th }}$. From the $24^{\text {th }}$ of February to April $19^{\text {th }}$ the $3: 2$ ratio, on average, gained $0.80 \mathrm{~g}$, confirming the best hormone ratio to initiate callus production in Canda. The 2:1 ratio was shown to be a good callus-initiating medium gaining, on average, $0.46 \mathrm{~g}$ from January $27^{\text {th }}$ - February $24^{\text {th }}$.

The maximum callus yielded by Joey was from a 3:1 ratio, weighing $6.63 \mathrm{~g}$ (Figure 7). The second largest amount of callus came from a 3:3 ratio, weighing $4.62 \mathrm{~g}$, while a $2: 2$ ratio yielded $4.61 \mathrm{~g}$. The best callus initiators, on average, were determined to be a 2:3 and also a 3:2 ratio, gaining $0.47 \mathrm{~g}$ of callus weight from February $16^{\text {th }}-$ March $17^{\text {th }}$ for both concentrations.

The maximum callus yielded by Landrace was at a 3:2 ratio weighing $3.21 \mathrm{~g}$

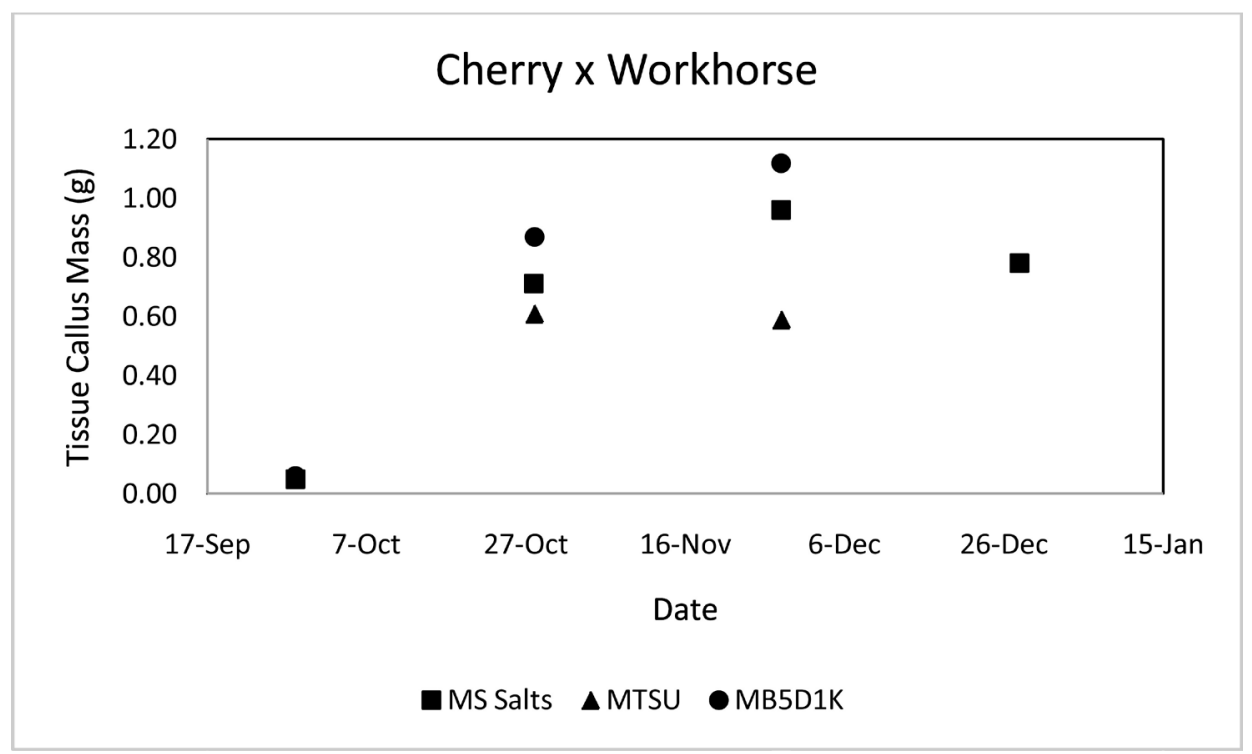

Figure 5. Cherry $\times$ Workhorse callus mass for MS salts, MTSU, and MB5D1K media from initial plating on September $28^{\text {th }}$ to final weight on December $28^{\text {th }}$. 


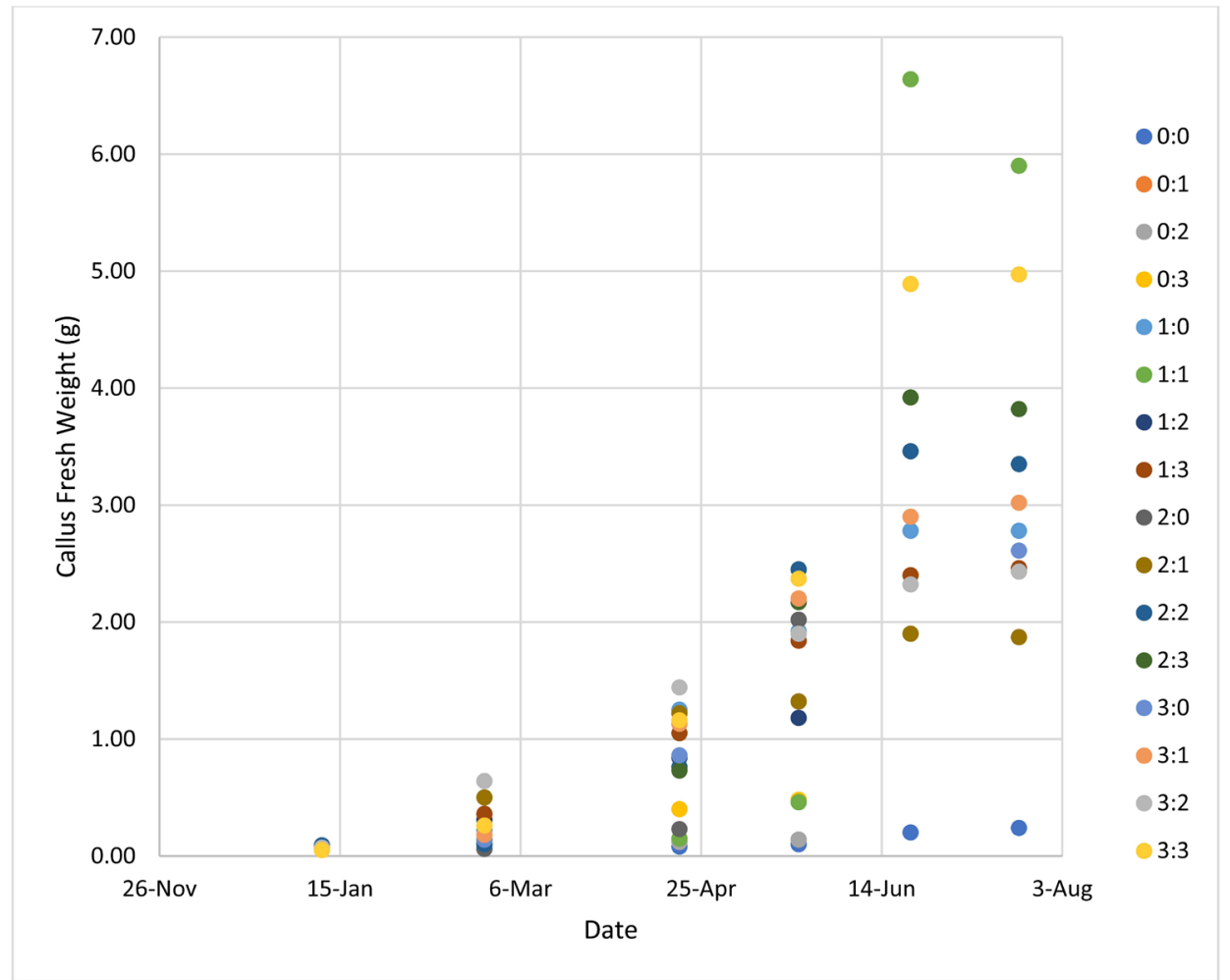

Figure 6. Canda change in callus mass for varying auxin:cytokinin concentrations from setup (November $26^{\text {th }}$ ) to completion (August $3^{\text {rd }}$ ).

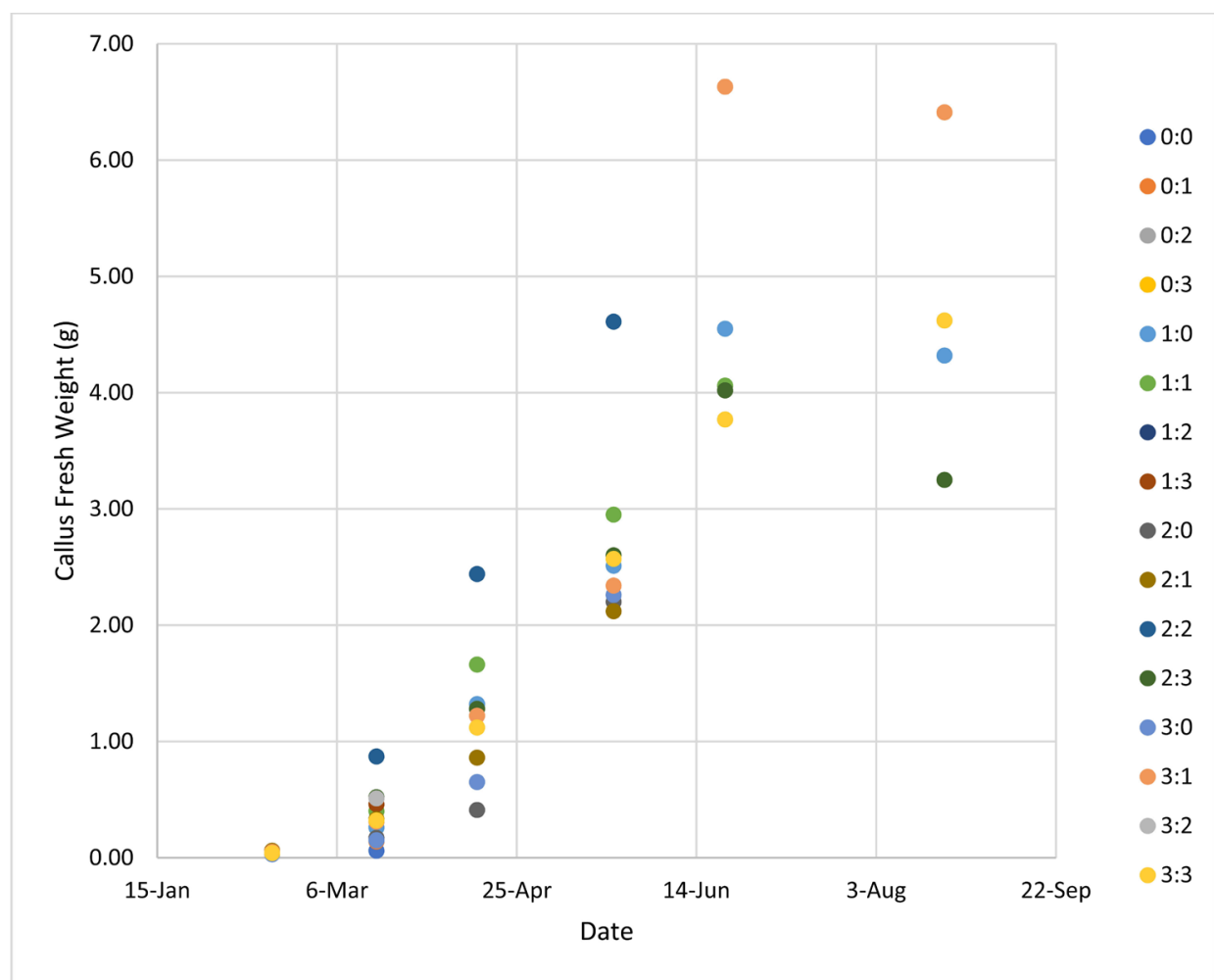

Figure 7. Joey change in callus mass for varying auxin:cytokinin concentrations from setup (January $15^{\text {th }}$ ) to completion (September $22^{\text {nd }}$ ). 


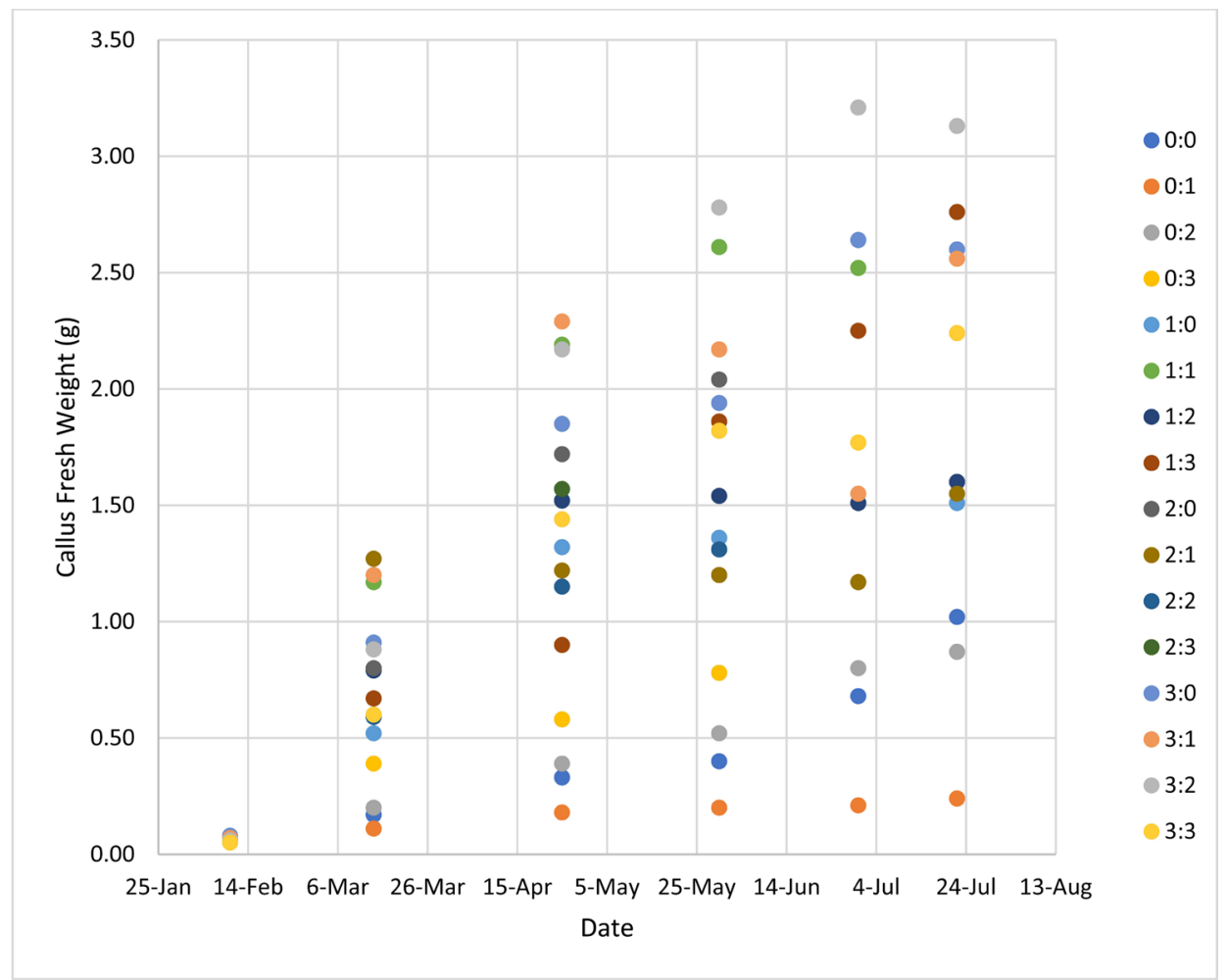

Figure 8. Landrace change in callus mass for varying auxin:cytokinin concentrations from setup (January $15^{\text {th }}$ ) to completion (August $3^{\text {rd }}$ ).

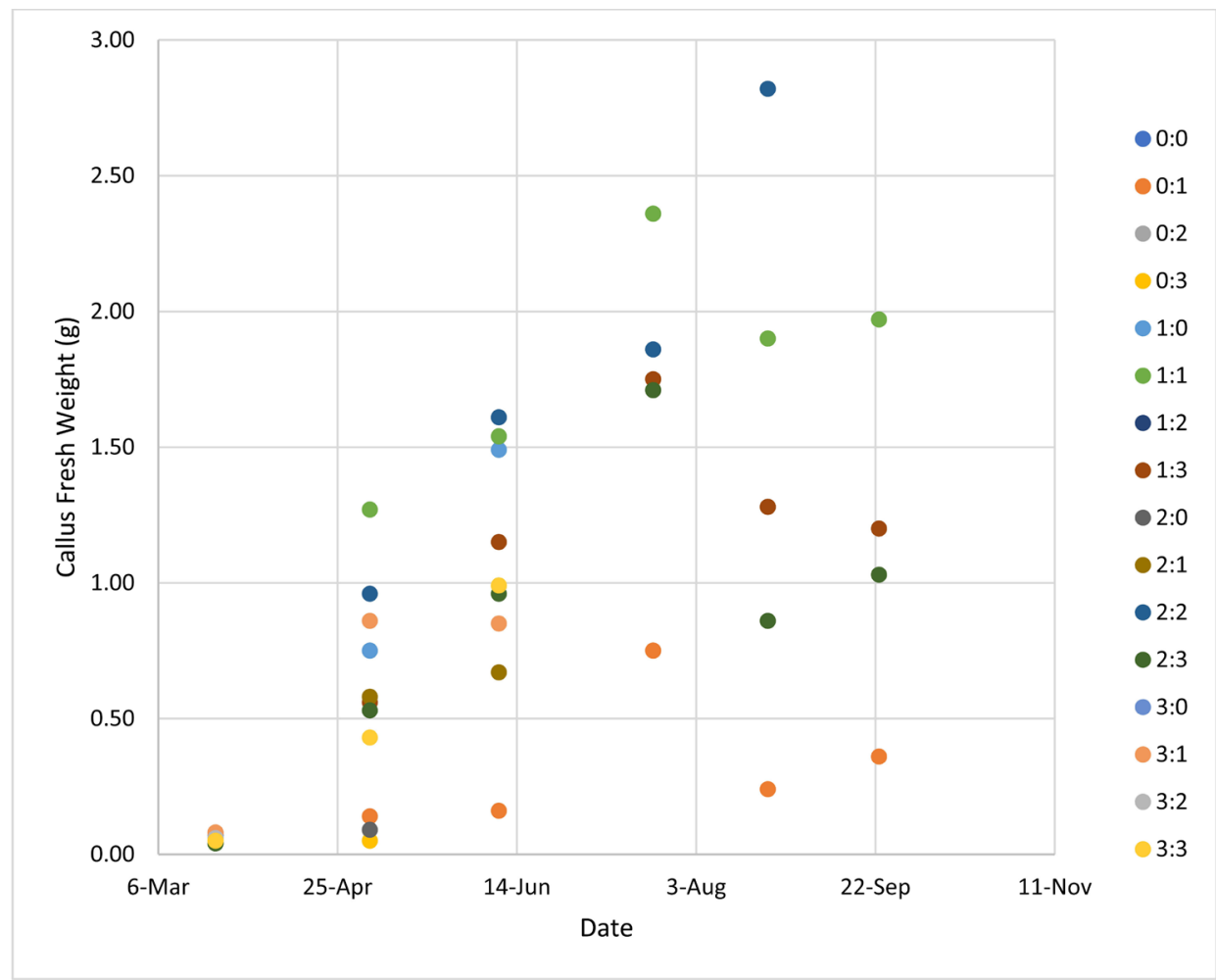

Figure 9. Futura change in callus mass for varying auxin:cytokinin concentrations from setup $\left(\right.$ March $\left.6^{\text {th }}\right)$ to completion (November $11^{\text {th }}$ ). 
(Figure 8). The second and third best yields came from a 3:2 ratio weighing 2.78 $\mathrm{g}$ and a 1:3 ratio weighing $2.76 \mathrm{~g}$. The best callus-initiating medium was determined to be a 2:1 ratio gaining, on average, $1.20 \mathrm{~g}$ from February $10^{\text {th }}$ - March $14^{\text {th }}$. The next best initiating medium was a 3:1 ratio gaining, on average, $1.13 \mathrm{~g}$ from February $10^{\text {th }}-$ March $14^{\text {th }}$.

The maximum callus yielded by Futura was by a 2:2 ratio, weighing $2.82 \mathrm{~g}$ (Figure 9). The second highest yield was from a 1:1 ratio weighing $2.36 \mathrm{~g}$. The best callus-initiating medium was determined to be 1:1 gaining, on average, 1.22 $\mathrm{g}$ of callus weight from March $22^{\text {nd }}-$ May $4^{\text {th }}$. The next best initiating medium was a 2:2 ratio and gained $0.89 \mathrm{~g}$ of callus weight from March $22^{\text {nd }}$ - May $4^{\text {th }}$.

The maximum yield of callus in CFX-2 was from a 2:3 ratio, weighing $2.53 \mathrm{~g}$ (Figure 10). The second highest occurred at a 3:2 ratio, weighing $1.98 \mathrm{~g}$. The best callus-initiating medium was determined to be a ratio of 2:3 gaining, on average, $0.65 \mathrm{~g}$ from April $14^{\text {th }}$ - May $22^{\text {nd }}$. The second best initiating medium was determined to be a 2:2 ratio gaining $0.60 \mathrm{~g}$ from April $14^{\text {th }}-$ May $22^{\text {nd }}$.

\section{Callus Growth Rates}

\section{Nutrient Salts}

Growth rates (mg/day) for callus are displayed in Figures 11-15. Canda showed a significant difference $(p<0.05)$ in growth rates between the MB5D1K and the other two media with the MB5D1K medium showing the highest growth rate (Figure 11).

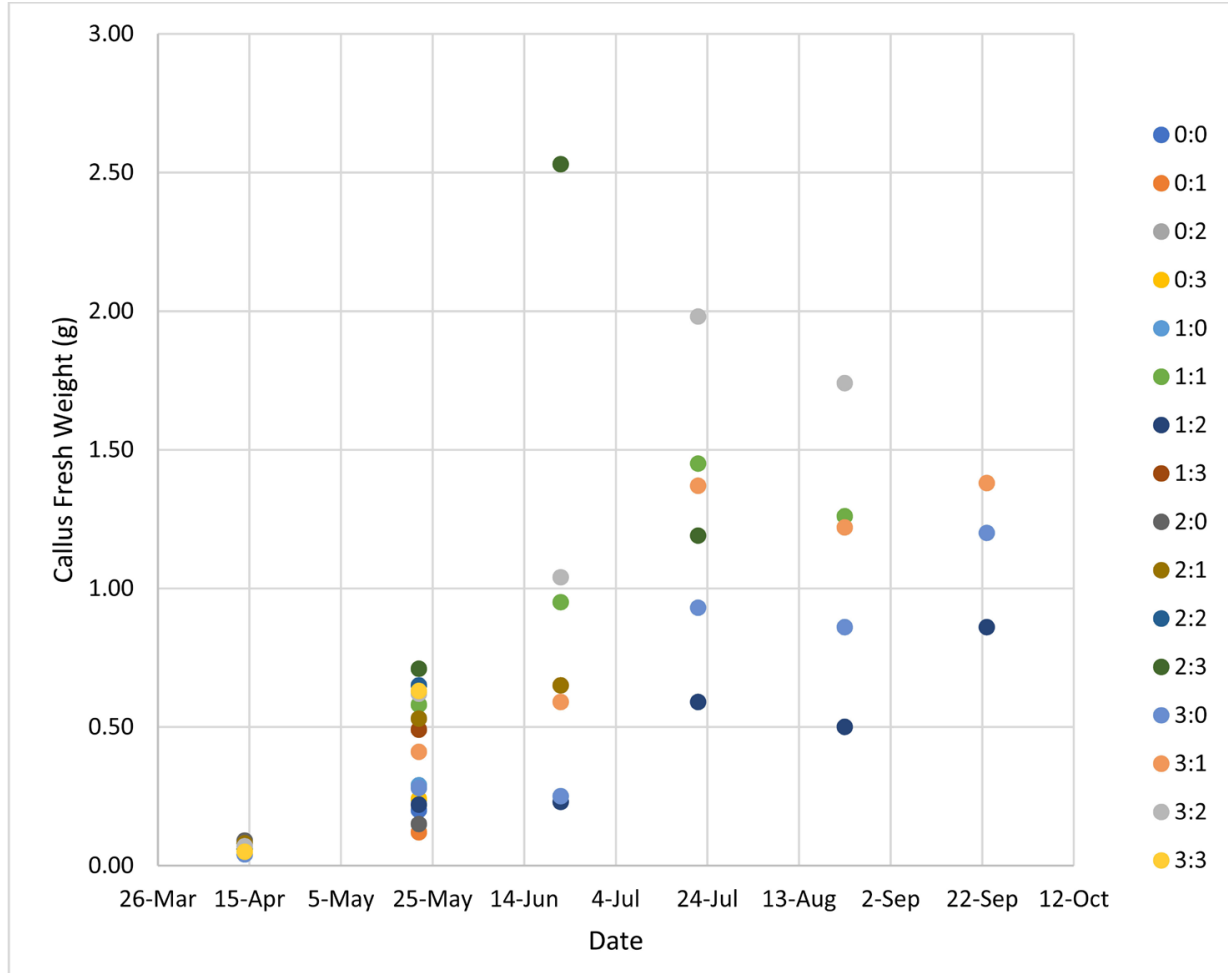

Figure 10. CFX-2 change in callus mass in varying auxin:cytokinin concentrations from setup (March $\left.26^{\text {th }}\right)$ to completion (October $\left.12^{\text {th }}\right)$. 


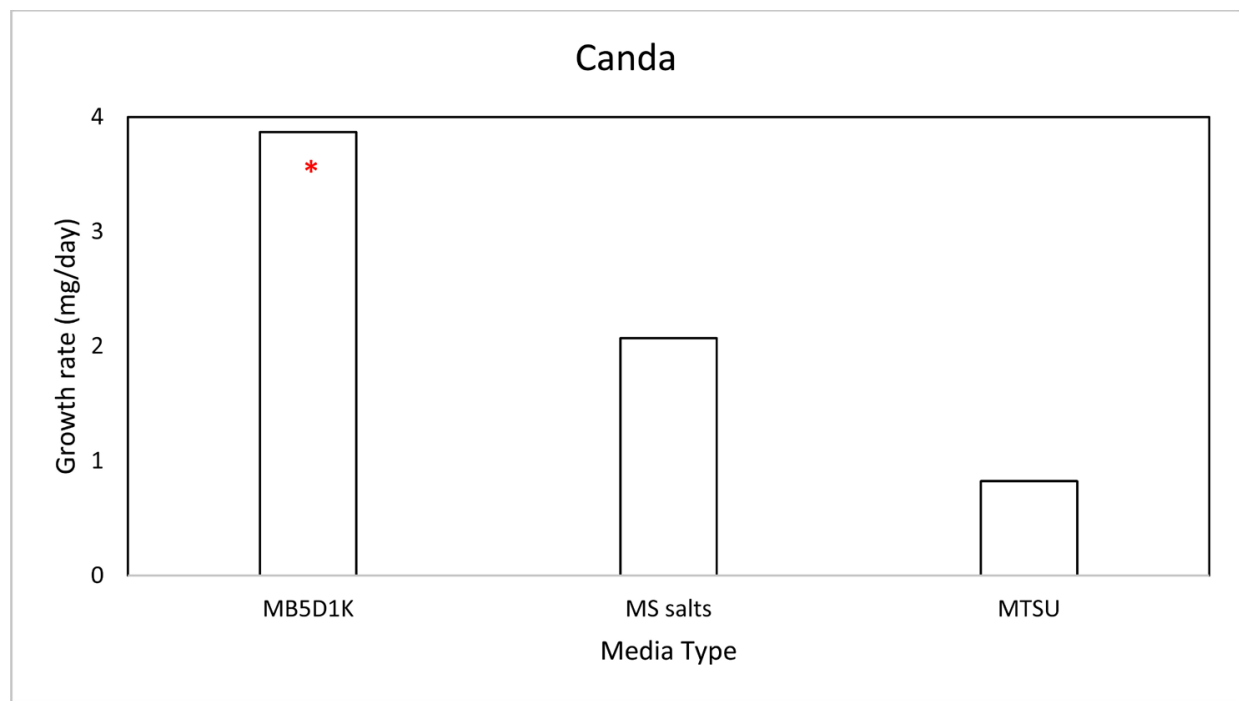

Figure 11. Callus growth rates over five months for Canda. ${ }^{\star}$ Indicates there was a significant difference $(\mathrm{p}<0.05)$ between MB5D1K and the other two media.

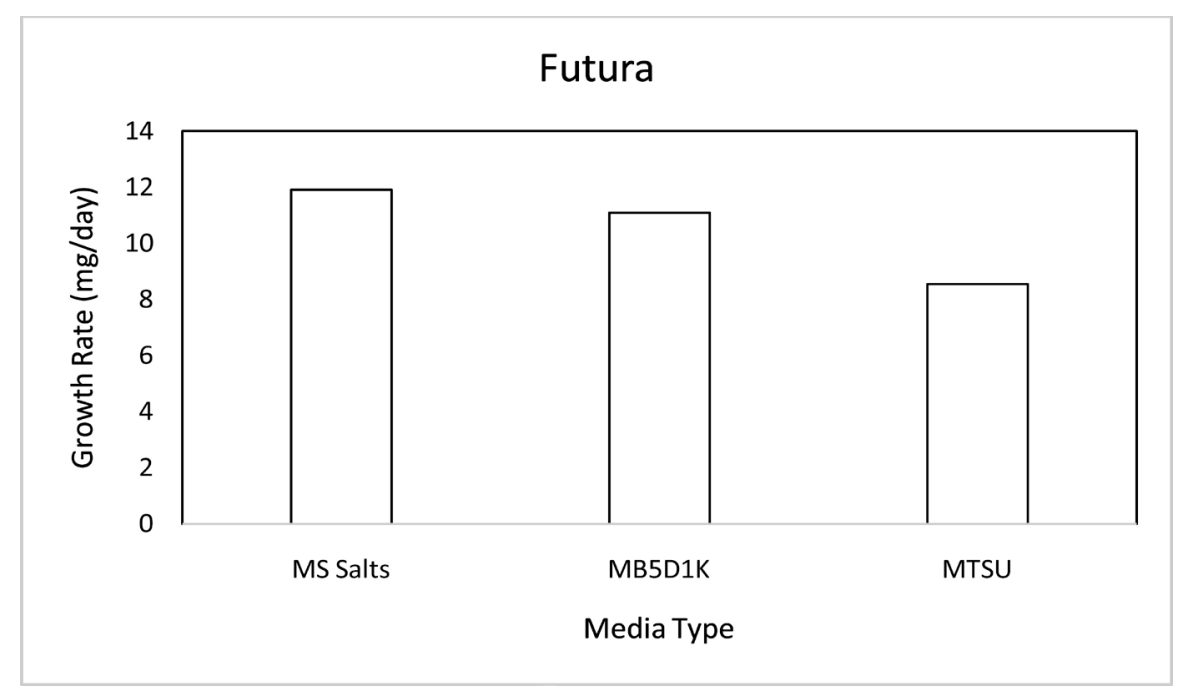

Figure 12. Callus growth rates over five months for Futura.

For Futura, there was no statistically significant difference between the media, but MS salts medium produced callus with the highest growth rate (Figure 12). Callus growth performed well on all media with MB5D1K medium coming in close at second for callus growth rate. For Joey, there was no statistically significant difference between the media, but the MS salts medium produced callus with the highest growth rate (Figure 13). For CFX-2 there was no statistically significant difference between the media, but the MS salts medium produced callus with the highest growth rate (Figure 14). For Cherry $\times$ Workhorse there was no statistically significant difference between the media, but the MB5D1K medium produced callus with the highest growth rate (Figure 15).

\section{Hormones}

Figures 16-20 highlight the growth rates (grams/day) over a five month period 


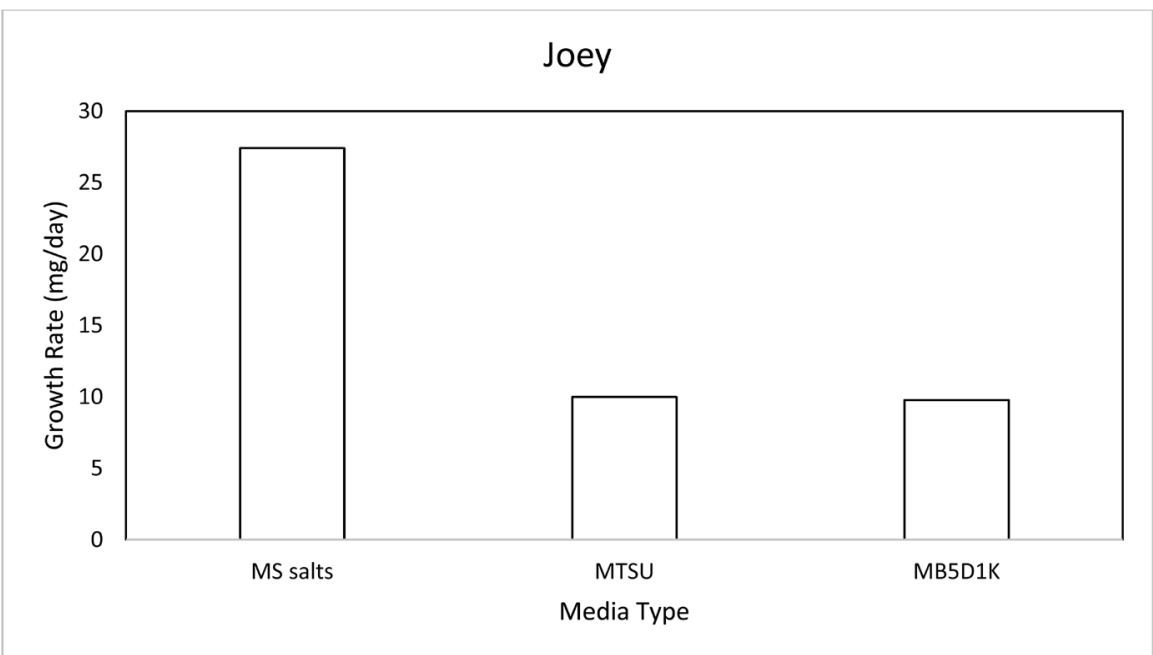

Figure 13. Callus growth rates over five months for Joey.

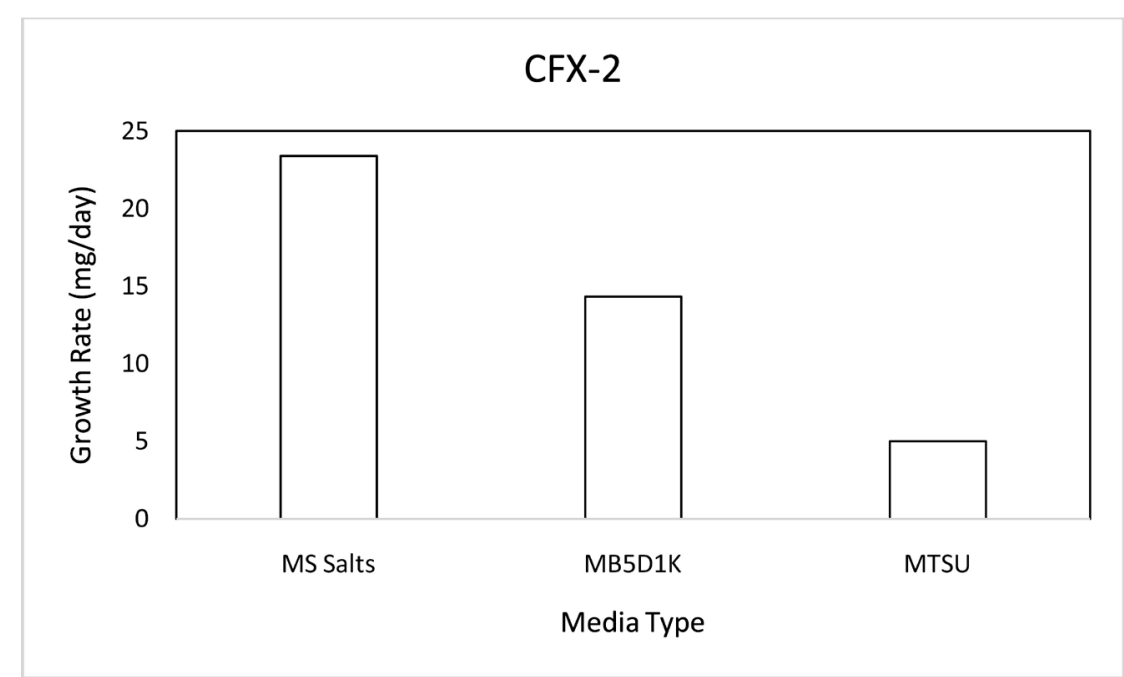

Figure 14. Callus growth rates over five months for CFX-2.

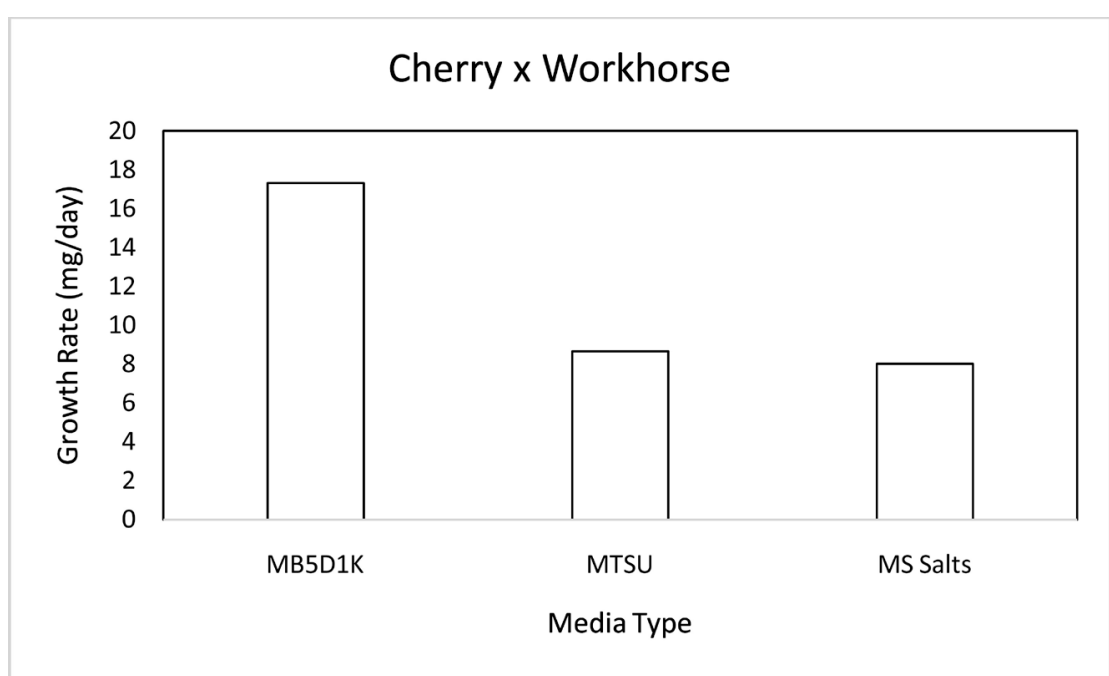

Figure 15. Callus growth rates over four months for Cherry $\times$ Workhorse. 
for each hormone concentration/ratio for each cultivar. For Canda, the 1:1 ratio yielded the highest callus growth rate over a five month period, with 3:3 also showing a high rate (Figure 16).

For Joey, the 2:2 ratio yielded the highest callus growth rate with the ratio 3:1 also showing a high rate (Figure 17). For Landrace, the 2:3 and 3:2 ratios yielded the highest growth rates and were very close. The 2:0 and 1:1 ratios were similar as well as the 1:3 and 3:0 ratios (Figure 18). For Futura, the 1:0 and 2:2 ratios yielded the highest rates (Figure 19), followed by 3:3, 3:1, and 1:1 ratios. For CFX-2, the ratios of 2:3, 2:2, 3:3, and 3:2 had the highest rates of growth (Figure 20).

\section{Optimal Media Formulation}

\section{Mineral Salts}

Table 2 shows the best media mineral salts formulations for each cultivar.

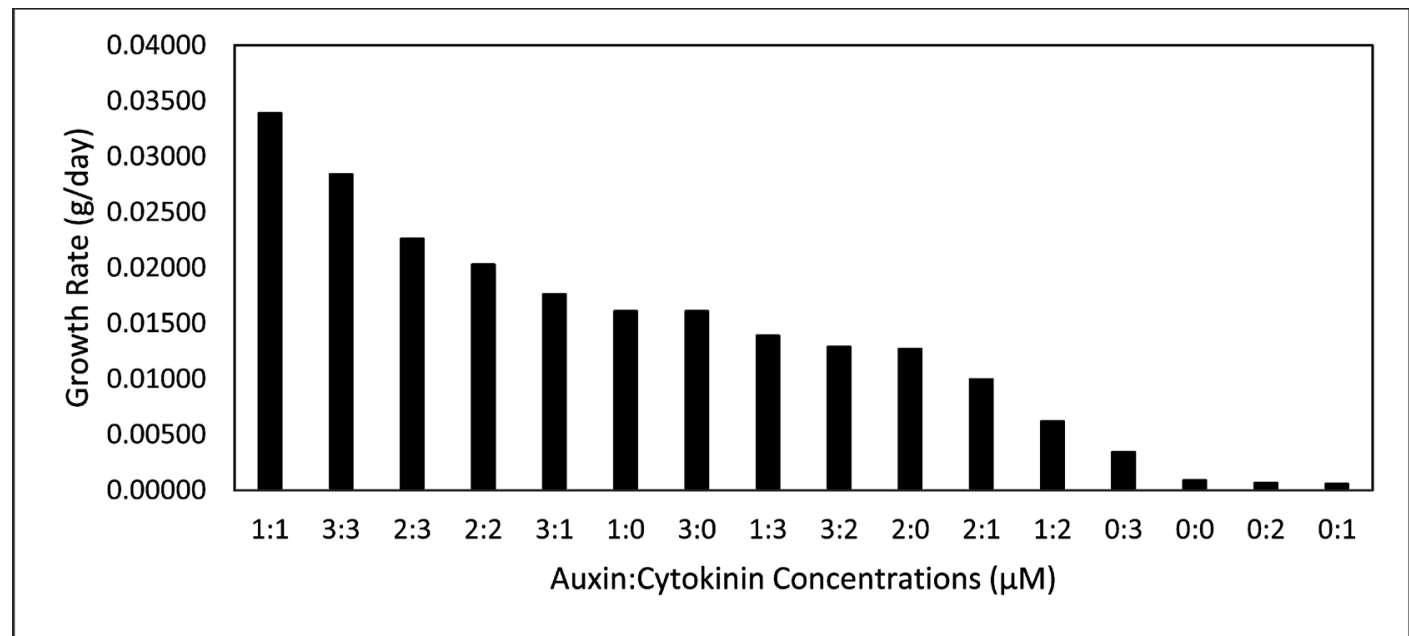

Figure 16. Canda callus growth rate over five months.

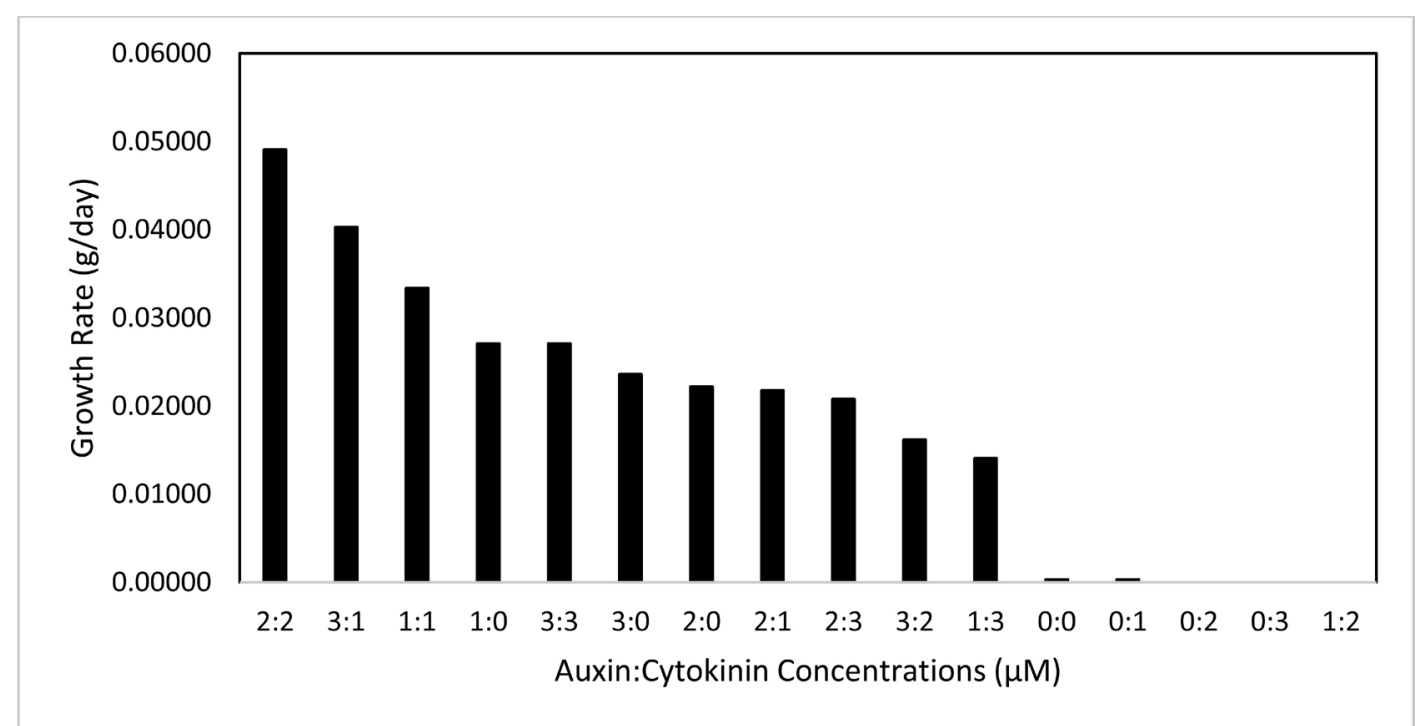

Figure 17. Joey callus growth rate over five months. 


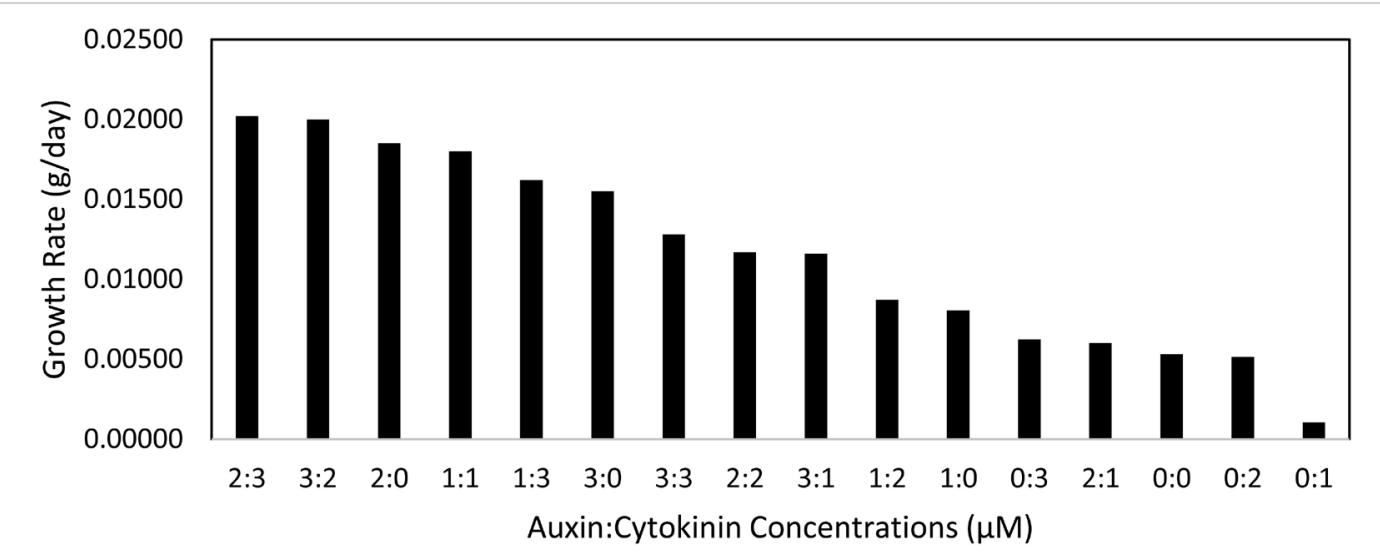

Figure 18. Landrace callus growth rate over five months.

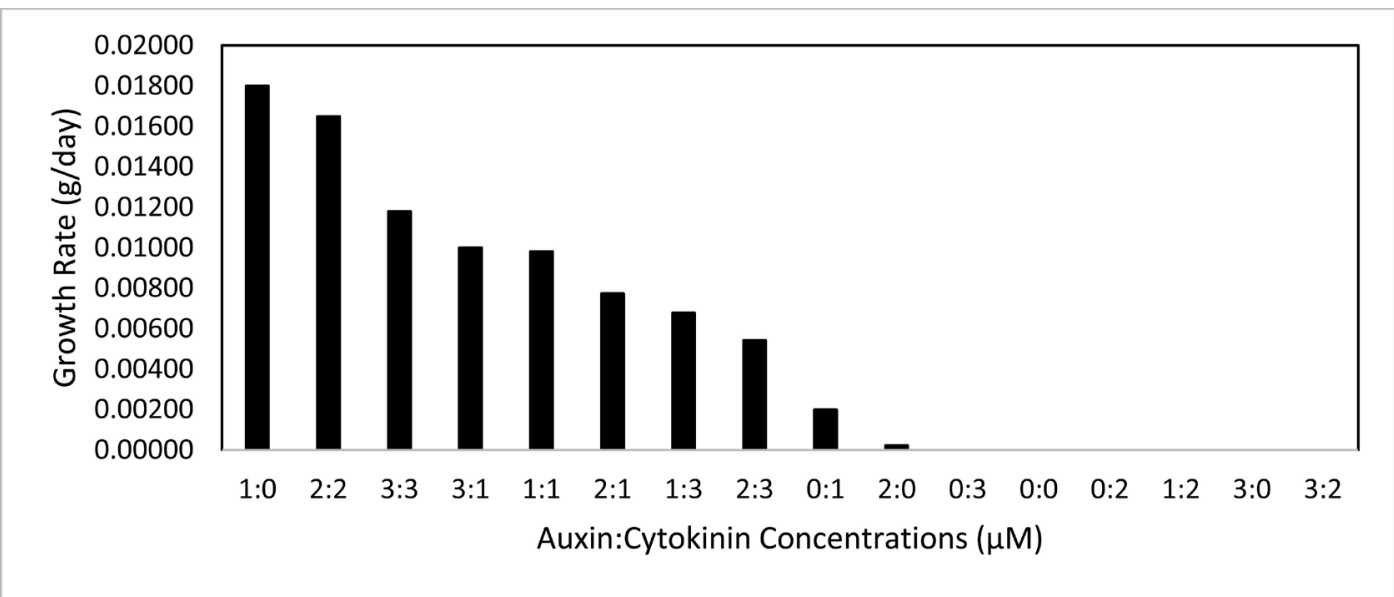

Figure 19. Futura callus growth rate over five months.

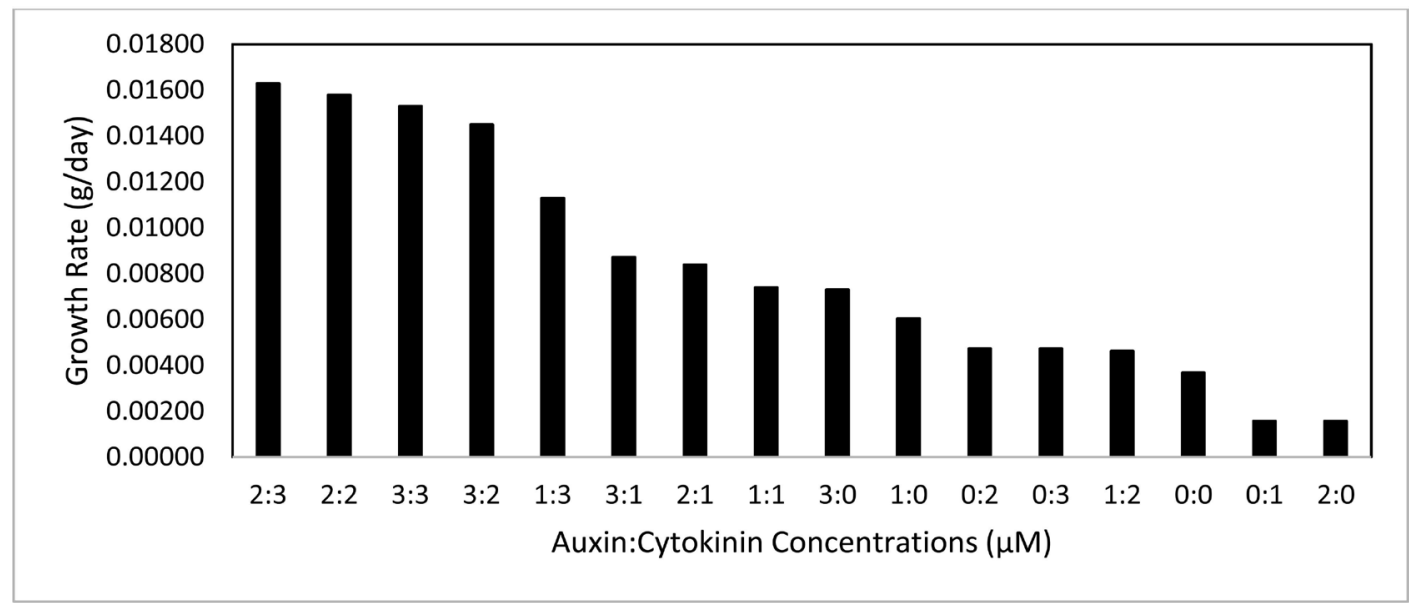

Figure 20. CFX-2 callus growth rate over five months.

Each media type is ranked in order of amount of callus produced and the growth rates. A rank of 1 means that medium was the best, and a rank of 3 indicates the media produced the least amount of callus growth with a lower growth rate. The 
MS salts medium was the top medium for the cultivars Joey, CFX-2, and Futura, while coming in second for the cultivar Canda and third for Cherry $\times$ Workhorse. The MB5D1K medium was the top medium for the cultivars Canda and Cherry $\times$ Workhorse, while coming in second for the cultivars CFX-2 and Futura. It came in third for the cultivar Joey. The MTSU medium was not the top medium for any cultivar, but came in second for Joey and third for the cultivars Canda, CFX-2, and Futura.

Table 3 takes the rankings of the media types from Table 2 and averages their scores to get a composite mean score. The lower the mean number, the higher the ranking of that medium for the five cultivars experimented. The MS salts medium had the lowest mean and was the top medium for 3 out 5 of the cultivars. It was followed closely by the MB5D1K medium that was the top medium for 2 out of the 5 cultivars.

\section{Hormones}

The best media formulations for callus growth for each cultivar are displayed in Table 4. Similar media formulations are highlighted with the same color. The auxin:cytokinin concentration/ratio of 2:2 was the top medium for callus growth in Joey and the second best for CFX-2 and Futura. It was also the fourth best for Canda. The media formulation of 1:1 was the best for Canda, third best for Joey, fourth best for Landrace and fifth best for Futura. The media formulation 3:3 was the second best for Canda, third best for CFX-2 and Futura, and the fifth best for Joey.

The top performing media formulations, along with the number of cultivars for which they were in the top five, are shown in Table 5. It is interesting to note

Table 2. The best media formulations ranked in order based on callus growth for each cultivar tested, 1 being the greatest callus growth and 3 being the least.

\begin{tabular}{cccc}
\hline \multirow{2}{*}{$\begin{array}{c}\text { Hemp } \\
\text { Variety }\end{array}$} & $\mathbf{1}$ & $\mathbf{3}$ & $\mathbf{3}$ \\
\cline { 2 - 4 } & MB5D1K & MS salts & MTSU \\
Canda & MS salts & MTSU & MB5D1K \\
Joey & MS salts & MB5D1K & MTSU \\
CFX-2 & MS salts & MB5D1K & MTSU \\
Futura & MB5D1K & MTSU & MS salts \\
\hline
\end{tabular}

Table 3. Media scores for the five cultivars tested, and the means and standard deviations of those scores. Scores are the representative rankings of the media effectiveness. A score of 1 represents the best medium and a score of 3 represents the least effective (see Table 2).

\begin{tabular}{|c|c|c|c|c|c|c|c|}
\hline Media & \multicolumn{2}{|c|}{ Scores } & & & & Mean & \multirow{2}{*}{$\begin{array}{l}\text { SD } \\
0.9\end{array}$} \\
\hline MS salts & 1 & 1 & 1 & 2 & 3 & 1.6 & \\
\hline MB5D1K & 1 & 1 & 2 & 2 & 3 & 1.8 & 0.8 \\
\hline MTSU & 2 & 2 & 3 & 3 & 3 & 2.6 & 0.5 \\
\hline
\end{tabular}


that the top three performing media formulations for four of the five cultivars are equal concentrations of auxin to cytokinin (1:1, 2:2, and 3:3).

The best media formulations for callus initiation are displayed in Table 6. Although there is not as clear of a pattern evident in this array, the ratios of $2: 1$, $2: 2,2: 3$, and $3: 2$ are effective for more than one cultivar.

\section{Discussion}

The purposes of this study were to determine: 1) the optimal media mineral salts and; 2) the optimal hormone concentration/ratio for callus induction and callus growth in Industrial Hemp (Cannabis sativa L.).

Table 4. The best five media formulations for callus growth for each of the five cultivars tested.

\begin{tabular}{cccccc}
\hline \multirow{2}{*}{$\begin{array}{c}\text { Hemp } \\
\text { Variety }\end{array}$} & $\mathbf{1}$ & $\mathbf{2}$ & $\mathbf{3}$ & $\mathbf{4}$ & $\mathbf{5}$ \\
\cline { 2 - 6 } & $2: 3$ & $3: 2$ & $2: 0$ & $1: 1$ & $1: 3$ \\
Landrace & $1: 1$ & $3: 3$ & $2: 3$ & $2: 2$ & $3: 1$ \\
Canda & $2: 2$ & $3: 1$ & $1: 1$ & $1: 0$ & $3: 3$ \\
Joey & $2: 3$ & $2: 2$ & $3: 3$ & $3: 2$ & $1: 3$ \\
CFX-2 & $1: 0$ & $2: 2$ & $3: 3$ & $3: 1$ & $1: 1$ \\
Futura & & & & & \\
\hline
\end{tabular}

Table 5. Top performing media formulations for the five cultivars of hemp tested. The numbers in parentheses indicates the number of cultivars for which that formulation was in the top five best media formulations.

\begin{tabular}{ccccc}
\hline \multirow{2}{*}{ Auxin $(\mu \mathrm{M})$} & \multicolumn{4}{c}{ Cytokinin $(\mu \mathrm{M})$} \\
\cline { 2 - 5 } & $\mathbf{0}$ & $\mathbf{1}$ & $\mathbf{2}$ & $\mathbf{3}$ \\
\hline $\mathbf{0}$ & $0: 0$ & $0: 1$ & $0: 2$ & $0: 3$ \\
$\mathbf{1}$ & $1: 0(2)$ & $1: 1(4)$ & $1: 2$ & $1: 3(2)$ \\
$\mathbf{2}$ & $2: 0(1)$ & $2: 1$ & $2: 2(4)$ & $2: 3(3)$ \\
$\mathbf{3}$ & $3: 0$ & $3: 1(3)$ & $3: 2(2)$ & $3: 3(4)$ \\
\hline
\end{tabular}

Table 6. The top performing formulations for callus-initiating media for the five cultivars tested.

\begin{tabular}{ccc}
\hline & Media Formulation Ranking & \\
\hline Hemp Variety & $\mathbf{1}$ & $\mathbf{2}$ \\
\hline Landrace & $2: 1$ & $3: 1$ \\
Canda & $3: 2$ & $2: 1$ \\
Joey & $2: 3$ & $3: 2$ \\
CFX-2 & $2: 3$ & $2: 2$ \\
Futura & $1: 1$ & $2: 2$ \\
\hline
\end{tabular}


There has been minimal research conducted on plant tissue culture systems specifically implemented on industrial hemp. Feeney and Punja [8] support the use of 2,4-D and kinetin as the optimal hormone growth regulators, finding that these produced greatest callus growth and also made for the best appearance of callus. However, they used a 5:1 ratio of auxin:cytokinin for their cultivars of interest. Slusarkiewicz-Jarzina et al. [9] found that DICAMBA, in concentrations of $9.05 \mu \mathrm{M}$ or $13.7 \mu \mathrm{M}$, alone produced the greatest amount of callus, which is interesting because DICAMBA is solely a cytokinin and contains no auxin. In this experiment, the majority of plates that contained no auxin tended to form roots (i.e. ratios like 0:1, 0:2, and 0:3). Minocha [10] suggested that the reason media lacking auxin produced roots was because of the availability of endogenous auxin in the plant occurring naturally. Jiang et al. [11] found that the optimal hormone concentration for callus initiation was a 4.4:2.7 ratio. They also found the optimal concentration for callus growth occurred at a 4.6:2.7 ratio. It is interesting to note that they found similar ratios to induce and grow callus.

Additionally, few studies have been conducted for determining optimal mineral salts or hormone formulations for Industrial Hemp. Feeney and Punja [8] used the MB5D1K medium formulation and it was shown to promote substantial callus growth. The MS salts medium formulated by Murashige and Skoog [5] was originally used to generate callus growth in tobacco for a study on cytokinins.

Results in our study show that three of the five cultivars (Joey, CFX-2, and Futura) responded well to the MS salts medium as far as callus mass produced and growth rates. Two of the five cultivars (Canda and Cherry $\times$ Workhorse) responded well to the MB5D1K medium with callus mass produced and growth rates. The results from the Canda experiment showed a significant difference between the MB5D1K medium and the other two. Because of the significant difference ( $\mathrm{p}<0.05$ ), the MB5D1K medium can be used to generate the best result of callus mass produced and the highest growth rate. This finding is substantiated by Feeney and Punja [8], who also used the MB5D1K medium.

There were specific hormone concentrations/ratios for the best callus-initiating media and the most callus growth. Interestingly, results showed that in four of the five cultivars tested, the top three media formulations for callus growth were equal concentrations of auxin to cytokinin (1:1, 2:2, 3:3). These cultivars include Canda, Joey, CFX-2, and Futura. Landrace had a 1:1 ratio as the fourth best ratio for callus growth, but it was not in the top three. The trend with callus-initiating media was not as easy to determine. The best media formulations determined for callus induction were 2:1, 2:2, 2:3, and 3:2. The best media formulation determined for callus growth was an equal concentration of auxin:cytokinin, however 2:2 showed up the most on the top 3 media formulations. It is important to realize that 2:2 was recognized as a good initiating media type, as well as, an excellent media type for maintaining callus growth.

In summary, Table 7 shows the top two media formulations for callus induction, 
Table 7. Top two media formulations for both callus induction and callus growth for each cultivar.

\begin{tabular}{ccccc}
\hline \multirow{2}{*}{ Cultivar } & \multicolumn{2}{c}{ Callus Induction } & \multicolumn{2}{c}{ Callus Growth } \\
\cline { 2 - 5 } & 1 & 2 & 1 & 2 \\
\hline Landrace & $2: 1$ & $3: 1$ & $2: 3$ & $3: 2$ \\
Canda & $3: 2$ & $2: 1$ & $1: 1$ & $3: 3$ \\
Joey & $2: 3$ & $3: 2$ & $2: 2$ & $3: 1$ \\
CFX-2 & $2: 3$ & $2: 2$ & $2: 3$ & $2: 2$ \\
Futura & $1: 1$ & $2: 2$ & $1: 0$ & $2: 2$ \\
\hline
\end{tabular}

and also callus growth, for each cultivar. This table shows that 2:2 is the most frequently occurring concentration/ratio. If one did not want to make different media types for induction and growth, then this experiment shows that 2:2 would be the most appropriate growth regulator for both purposes.

\section{Acknowledgements}

This research was partially funded by Greenway Herbal Products. X.T and K.T thank the Honors College of MTSU for their support.

\section{Conflicts of Interest}

The authors declare no conflicts of interest regarding the publication of this paper.

\section{References}

[1] Kaiser, C., Cassady, C. and Ernst, M. (2015) Industrial Hemp Production. Center for Crop Diversification, Cooperative Extension Service, University of Kentucky Agriculture, Food, and Environment, 6 p.

[2] Alcohol \& Drug Abuse Institute (ADAI) (2013) Cannabinoids. University of Washington. http://learnaboutmarijuanawa.org/factsheets/cannabinoids.htm

[3] Scuderi, C., Filippis, D. and Iuvone, T. (2009) Cannabidiol in Medicine: A Review of Its Therapeutic Potential in CNS Disorders. Phytotherapy Research, 23, 597-602. https://doi.org/10.1002/ptr.2625

[4] Murashige, T. (1974) Plant Propagation through Tissue Cultures. Annual Review of Plant Physiology, 25, 135-166. https://doi.org/10.1146/annurev.pp.25.060174.001031

[5] Murashige, T. and Skoog, F. (1962) A Revised Medium for Rapid Growth and Bio Assays with Tobacco Tissue Cultures. Physiologia Plantarium, 15, 473-497. https://doi.org/10.1111/j.1399-3054.1962.tb08052.x

[6] Leguillon, S., Charles, G. and Branchard, M. (2003) Plant Regeneration from Thin Cell Layers in Spinacia oleracea. Plant Cell, Tissue and Organ Culture, 74, 257-265. https://doi.org/10.1023/A:1024042522940

[7] Odnevall, A., Bjork, L. and Berglund, T. (1989) Rapid Establishment of Tissue Cultures from Seeds of Panax ginseng and Panax pseudoginseng. Biochemice und Physiologie der Pflanzen, 185, 131-134. https://doi.org/10.1016/S0015-3796(89)80169-6 
[8] Feeney, M. and Punja, Z.K. (2003) Tissue Culture and Agrobacterium Mediated Transformation of Hemp (Cannabis sativa L.). In Vitro Cellular \& Developmental Biology_Plant, 39, 578-585. https://doi.org/10.1079/IVP2003454

[9] Slusarkiewicz-Jarzina, A., Ponitka, A. and Kaczmarek, Z. (2005) Influence of Cultivar, Explant Source, and Plant Growth Regulator on Callus Induction and Plant Regeneration of Cannabis sativa L. Acta Biologica Cracoviensia Series Botantica, 47, 145-151.

[10] Minocha, S.C. (1987) Plant Growth Regulators and Morphogenesis in Cell and Tissue Culture of Forest Trees. In: Bonga, J.M. and Durzan, D.J., Eds., Cell and Tissue Culture in Forestry. Forestry Sciences, Vol. 24-26, Springer, Dordrecht. https://doi.org/10.1007/978-94-017-0994-1_4

[11] Jiang, Y., Xia, Z., Tang, Y., Han, Q. and Han, C. (2015) Preliminary Studies on the Tissue Culture of Cannabis sativa L. (Industrial Hemp). Agricultural Science \& Technology, 16, 923-925. 